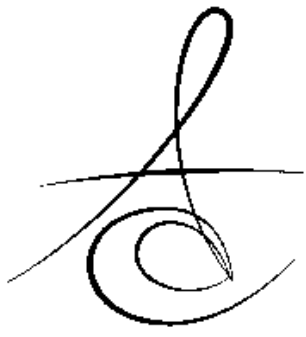

\title{
ÇİFT TARAFLI DUDAK DAMAK YARIKLI HASTANIN HAREKETLİ PROTEZLER İLE PROTETİK REHABİLITTASYONU: VAKA SUNUMU
}

\section{PROSTHETIC REHABILITATION OF A PATIENT WITH BILATERAL CLEFT LIP AND PALATE USING REMOVABLE PROSTHESIS: A CASE REPORT ${ }^{*}$}

\author{
Dr. Sinem OK ${ }^{*}$ \\ Yrd. Doç. Dr. Y. Umut ASLAN*
}

\author{
Doç. Dr. Şebnem. Begüm TÜRKER* \\ Prof. Dr. Yasemin ÖZKAN*
}

Makale Kodu/Article code: 2713

Makale Gönderilme tarihi: 24.03.2016

Kabul Tarihi: 07.04.2016

\section{ÖZ}

Dudak damak yarığı (DDY) hamilelik sırasında yüzün anormal gelişimi sonucu dudak ve damak bölgesinde yarık oluşmasıyla karakterize konj enital bir anomalidir. DDY'nın kesin etiyolojisi bilinmemektedir. Dudak damak yarığı olan hastalarda; estetik, fonetik, fonksiyonel ve önemli psikolojik problemlere yol açmaktadır. $\mathrm{Bu}$ tip hastalarda protetik rehabilitasyonun öncelikli amacı maksiller defekti kapatmak ve farklı bulb dizaynı olan protezlerle benzer problemleri ortadan kaldırmaktır. Obtüratörler maksilladaki defektlerin kapatılmasında kullanılan bir tedavi yöntemidir. Defektin büyüklüğü ve lokalizasyonu hastanın klinik durumunu etkiler ve protetik rehabilitasyonun zorluğunu belirler. Dudak damak yarığı olan hastalar konvansiyonel protezler ile tedavi edilebilirler.

Bu vaka sunumunda Marmara Üniversitesi Dişhekimliği Fakültesine başvurmuş olan 33 yaşındaki dudak damak yarıklı hastanın tedavi basamakları anlatılmaktadır. Hastanın klinik muayenesinde; büyük bir oronasal açıklık, sert damaktaki defekti saran hiperplastik yumuşak doku, maksilladaki sol 1. premolar numaralı dişi ve dişsiz mandibula tespit edildi. Hastanın çiğneme fonksiyonun yeniden sağlamak, konuşmasını ve estetiğini geliştirmek amacıyla oronasal açıklığı kapatmak için maksillaya hareketli bölümlü protez, mandibulaya tam protez planlanmıştır ve hastanın tedavisi tamamlanmıştır. Hasta protezini 1 yıldır kullanmaktadır. Konuşması önemli ölçüde gelişmiştir, hastanın estetik ve fonksiyonel beklentileri karşılanmıştır.

Anahtar Kelimeler: dudak damak yarığı, protetik rehabilitasyon

\section{ABSTRACT}

The Cleft Lip and Palate (CLP) is variation of a type of clefting congenital anomaly caused by abnormal facial development during pregnancy. The etiology of CLP is unknown. Cleft lip and palate leads to esthetic, phonetic, functional and important psychological problems for the patient. The primarily aim of prosthetic rehabilitation is to close the maxillary defect and eliminate such problems by use of different bulb designs. An obturator is a treatment modality for the defects in maxilla. The size and location of the defects influence the patients clinic status and determine difficulty in prosthetic rehabilitation. Cleft lip and palate patients may reconstructed with conventional prosthesis.

This case study was reported the treatment steps of a 33 year old female with bilateral cleft lip and palate patient was referred to Marmara University Faculty of Dentistry. Preoperative clinical examination of patient with bilateral cleft lip and palate revealed a large oronasal communication, hyperplastic soft tissue surrounding the hard palate defect, severely resorbed alveolar ridge, maxiller left 1 . premolar teeth, edentulous mandible. A maxillary removable partial denture and a complete denture prosthesis were designed to cover the oronasal communication in the hard palate, to restore masticatory function, improve speech and esthetics. The patient has been wearing the prosthesis for 1 year. Her speech quality has greatly improved, and her esthetic and functional expectations have been met.

Key words: Cleft lip and palate, prothetic rehabilitation.

\footnotetext{
* Marmara Üniversitesi Diş Hekimliği Fakültesi Protetik Diş Tedavisi Anabilim Dalı

₹ 5.Uluslararası Türk Prostodonti ve İmplantoloji Derneği Bilimsel Sempozyumunda poster olarak sunulmuştur (18-20 Mart 2016, Erzurum-Turkey).
} 


\section{GİRIŞ}

Dudak damak yarığı fonksiyonel olarak hastaların çene- yüz yapısını bozan, aynı zamanda estetik olarak hastayı etkileyen doğumsal bir anomalidir. Dudak damak yarıklı bireylerde uzun süreli takip ve tedavi gerektiren bir yaklaşım izlenmelidir. Uterus içi yaşamda, fetüsün dudak yapısını oluşturan hücrelerin birleşmesi 4 veya 5 . haftada, damak yapısını oluşturan hücrelerin birleşmesi ise 8 veya 9 . haftada başlamaktadır. 12. haftanın sonunda, fetüsün damak ve dudak dokularının birleşmesi tamamlanmış olur. ${ }^{1}$

Damak yarığı ile beraber olan/olmayan dudak yarıkları ile izole damak yarıkları embriyolojik, etyolojik, epidemiyolojik faktörler ve kalitımlarından dolayı birbirinden farklı iki klinik durumdur ve ayrı olarak değerlendirilmelidir. ${ }^{2}$

Dudak damak yarıklı hastalarda eğer birleşme tam olarak gerçekleşemez ise fetüste oral yarıklar meydana gelebilir. Nazal ve maksiller bölgede bulunan bu yarıklar, bulunduğu bölgenin fonksiyonlarını etkileyebilmektedir. Yarığın bulunduğu yere bağı olarak, maksillanın yapısı, dişler, dudak ve yanaklar olumsuz olarak değişebilmekte, hatta solunum ve yutma fonksiyonlarında yetersizlikler meydana gelebilmektedir Dudak damak yarıklı çocuklarda primer dudak ve damak onarımları sonrası oluşan skar dokusuna (rekonstrüksiyon sonrası) bağlı olarak ise üst çenede dentoalveoler seviyede daralma ， gelişim geriliği ve alt ve üst dentoalveoler arklar arasındaki uyum bozukluğuna bağlı çapraz kapanış, ilişkisi gelişmektedir. Bu uyumsuzluk miktarı, büyüme ile üst dentoalveoler yapıların aleyhine olacak şekilde artmaktadır. Üst ve alt çenenin boyut ve şekli olumsuz etkilenmekte, üst çene retrognatik ve hipoplastik gelişebilmektedir. Bunun yanında, yarık hattında kalan dişler ya gelişmemekte ya da atipik formda ve pozisyonda kalmaktadır. Sonuç olarak nazomaksiller yapıdaki bu yarık çiğneme, konuşma ve solunum fonksiyon bozuklukları ile estetik ve psikososyal problemlere yol açmaktadır. ${ }^{3,4}$

Dudak-damak yarı̆ı̆ hikayesi bulunan bir ailede çocuğun dudak-damak yarıkı doğma riski artabilmekte ama bunun genetik açıklaması net olarak yapılamamaktadır. Orofasiyal yarıkların yaklaşık \%20'sini oluşturan sendromik yarıklarda basit Mendelian tipi kalııım olduğu bilinirken , sendromik olmayan yarıkların genetik kalıtımın da ki belirsizlikler devam etmektedir. Sendromik hasta grubunda sıklıkla yarık bölgesi dışında anatomik organ anomalileri ve mental retardasyon da tabloya eşlik eder. Dudak damak yarı̆ı̆ ile beraber görülen sendromlar; Van der woude sendromu, ektodermal displazi, ectrodactyly, opitz sendromu ve wolf-hirschhorn sendromudur. İzole damak yarı̆ı̆ ile beraber görülen sendromlar; Treacher collins sendromu, holoprosencephaly sendromu, stickler sendromu'dur. ${ }^{5}$

Dudak ve damak yarıkları embriyolojik dönemde çeşitli faktörlerin etkisi ile oluşmaktadır. Bunlar; antiepileptik ilaç kullanımı ， enfeksiyon, toksisite, kötü beslenme, hormonal dengesizlikler, folik asit eksikliği, yüksek doz retinoik asit, $B_{6}$ ve $B_{12}$ vitamin eksikliği , nikotin ve alkole maternal maruz kalma, annenin yası, ozon gazı artışıdır. ${ }^{6}$

Dudak damak yarığı etyolojisi incelenecek olursa; populasyon ve bulunduğu etnik grup önem kazanır. Bu vakalar en sık; Amerikan yerlileri ve Asyalılarda gözlenirken, beyaz ırkta orta sıklıkta, siyah ırkta ise en az sıklıkta gözlenir. Bu durumun en çok gözlendiği toplumlar ise Çin, Hindistan, Endonezya ve Pakistan'dır. ${ }^{7}$

Dudak damak yarıklı bireylerin tedavi planlaması, hastada mevcut bulunan defektin büyüklüğüne, eğer var ise dişlerin sağlıklı olup olmamasına, hastanın sosyo-ekonomik durumuna bağı olarak değişir. Hasta için planlanan protetik tedaviler sadece eksik dişlerin restore edilmesi dışında, ortodonti ve cerrahinin yarı̆ı̆ın kapatılmasına yetmediği durumlarda, hastanın yarığının kapatılması, konuşma, çiğneme ve estetik fonksiyonlarının iyileştirilmesi adına büyük önem kazanmaktadır. ${ }^{8}$ Çalışmanın amacı, hiçbir mültitidisipliner tedavi görmemiş dudak damak yarıkı bayan hastanın protetik tedavi basamaklarını ve anlatılmasıdır.

\section{VAKA SUNUMU}

Üst çenesinde dudak damak yarı̆ı bulunan 30 yaşındaki bayan hasta, konuşma, yeme ve estetik problemlerinin giderilmesi için fakültemize başvurdu. Tedavi öncesi hastadan alınan anamnezde, çift taraflı dudak yarığı ile doğduğu ve bu durumun düzeltilebilmesi adına herhangi bir tedavi görmediği belirlendi. Mevcut dudak damak yarığı ile ilgili ailesel geçmiş sorgulandığında, ailesinde başka dudak damak yarıklı birey bulunmadığı, sigara, alkol veya herhangi bir ilaç kullanmadığı tespit edildi.

Hastanın ağız içi muayenesi esnasında; çift

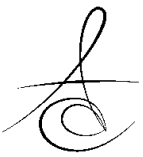


taraflı ve sert damakta bulunan yumuşak damağa kadar devam eden yarık tespit edildi. (Resim 1). Hastanın klinik ve radyolojik muayenesinde ağızda sadece periodontal ve endodontik olarak sağlıklı 24 no'lu dişin olduğu tespit edildi. Çift taraflı dudak damak yarığının cerrahi yöntemlerle kapatılıp kapatılamayacağı fakültemiz ağız diş çene cerrahları ile konsülte edildi, ancak hasta herhangi bir cerrahi operasyon geçirmek istemediğini bildirdi. İlgili dişin yapılacak protezde destek diş olarak kullanılabileceğine karar verildi. Ağız dışı muayenesinde ise dudak yarığına bağlı olarak skar dokusu gözlendi, estetik görünümü etkileyen herhangi bir asimetri görülmedi.

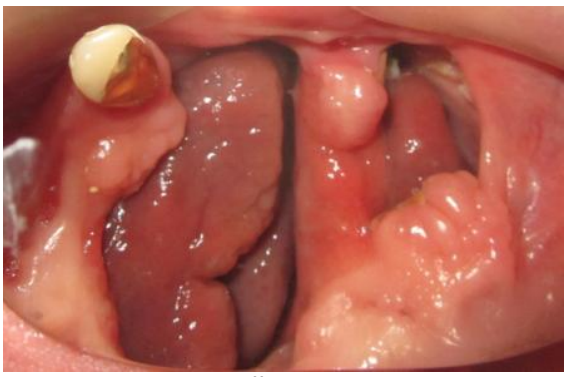

Resim 1- Hastanın ağız içi görüntüsü

Hastanın teşhis modelleri elde edilerek protetik planlaması yapıldı. Hastamızın estetik ve diğer kaybedilmiş fonksiyonlarını karşılayabilmek için 24 nolu dişin metal seramik kron restorasyonu ile restore edilmesine, üst çene defekt bölgesinin hareketli bölümlü parsiyel protez ile kapatılmasına, alt dişsiz çeneye tam protez yapılmasına karar verildi. Alt, üst çene teşhis modellerine kaide plakları hazırlandı, hastanın dikey boyutu belirlendi. Ağızda bulunan 24 nolu diş, chamfer bitim çizgisine sahip basamak ile prepare edildi. Diş retrakte edildi. Ölçü aşamasına geçildiğinde ölçü maddesinin defekt bölgesine kaçmasını engellemek amacıyla vazelin uygulanmış steril gaz tamponlar yarığın içerisine yerleştirildi. Bir numaralı fabrikasyon ölçü kaşığı ile silikon esaslı ölçü maddesi (Zetaflow, Zhermack, Badia Polesine,İtalya) ile hareketli protezin sabit kısmı için tek aşamalı ölçü işlemi gerçekleştirildi. (Resim 2). Elde edilen modeller yarı ayarlanabilir artikülatöre (Stratos 300, Ivoclar Vivadent, Inc, Avusturya) aktarıldı.

Laboratuvarda hazırlanan metal alt yapının kontrolü yapıldıktan sonra hasta ile birlikte yapılacak protez için renk belirlendi. (Resim 3). Renk seçimi sonrası tekrar laboratuvara gönderilen metal alt yapıya porselen işlenerek kronun estetik ve fonksiyonel uyumu kontrol edildi. Hastadan daha önceden elde edilen modeller üzerinde bireysel kaşıklar üretildi. Defekt bölgesi tekrar vazelinli streil tamponlar ile dikkatlice kapatıldıktan sonra kron restorasyon ağız içerindeyken polieter ölçü maddesi ile (Hydrorise Monophase, Zhermack, Badia Polesine, İtalya) hareketli bölümlü protezin ölçüsü alındı. (Resim 4). Alınan ölçü ile elde edilen yeni modelde protezin iskelet kısmı üretildi ve mum duvar aşamasında hastanın vertikal ve horizontal ilişkileri kaydedildi. Seçilen uygun boyuttaki yapay dişler ile dişli prova yapıldıktan (Resim 5) sonra protezin bitim aşaması tamamlandı. (Resim 6). Protezin hasta ağzında sentrik, lateral ve protrüziv hareketlerde kontrolleri yapılarak protezde bilateral balanslı oklüzyon sağlandı. Üretilen protezde defekt bölgesini rahatsız eden akrilik kısımlar aşındırılarak bu bölgelere yumuşak astar materyali (Viscogel, Dentsplay, GmbH, Konstanz, Almanya) uygulandı. (Resim 7). Hastanın, 24 saatlik kullanım süresi sonunda hastadan üst protezler alındı ve protezlerin daimi yumuşak astar materyali (Molloplast B, Detax, GmbH\&Co. KG, Ettlingen, Almanya) ile bitirilmesi için restorasyon laboratuvara gönderildi. (Resim 8). Protezler ile hastanın estetik, fonksiyonel, fonetik ve psikolojik problemleri rehabilite edildi. Bir yıllık klinik takip sonucunda protezlerin uyumunda ve balansında herhangi bir problemle karşılaşılmamış, hastanın beklentileri karşılanmıştır.

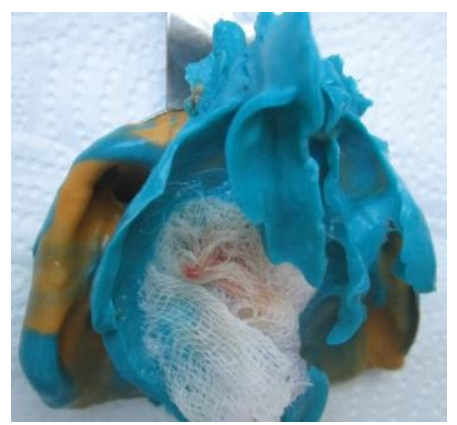

Resim 2- Hastanın üst çene diş kesimi sonrası ölçüsü 


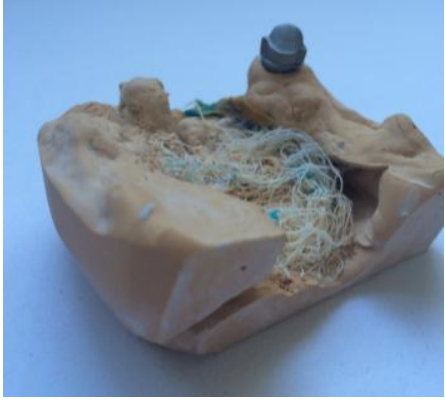

Resim 3- Hastanın sabit protezinin metal alt yapıSı

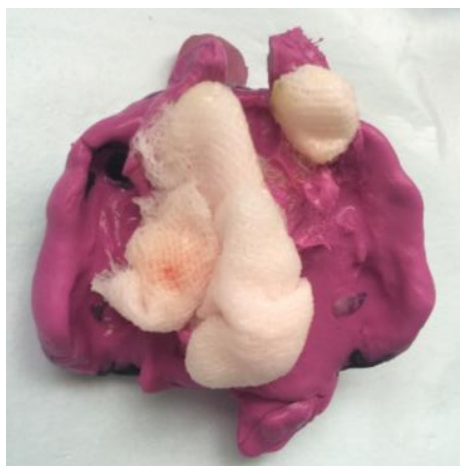

Resim 4- Polieter ölçü maddesi ile ölçü alımı

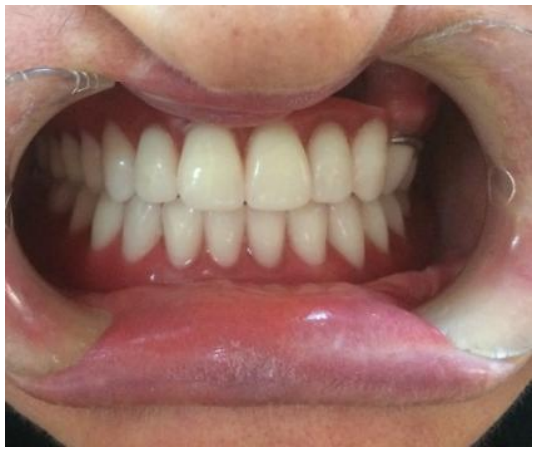

Resim 5- Dişli prova safhası

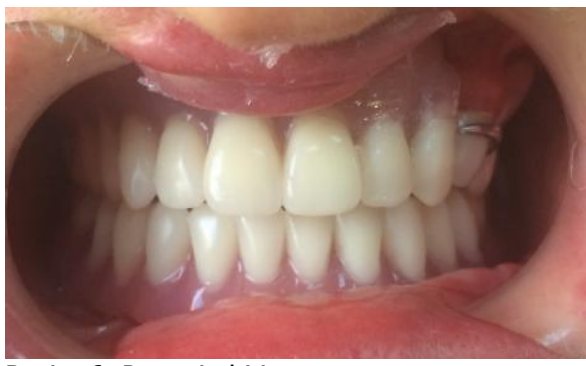

Resim 6- Protezin bitim aşaması

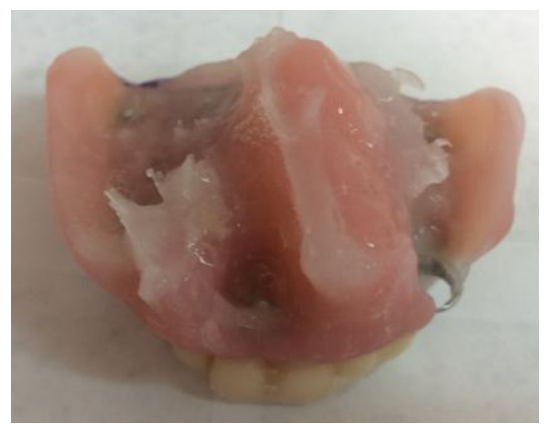

Resim 7- Yumuşak astar materyali uygulaması

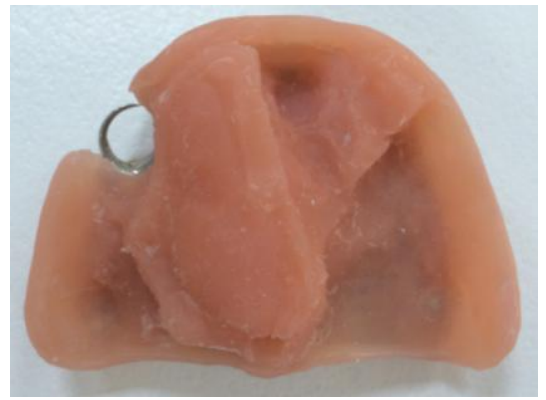

Resim 8: Molloplast B uygulaması

\section{TARTIŞMA}

Dudak damak yarığı olan bireylerin eğer mümkün ise ortodontik ve cerrahi tedavileri bittikten sonra hastanın büyüme ve gelişme dönemini tamamlamasıyla birlikte çoğu zaman protetik rehabilitasyonu gerekmektedir. Protetik rehabilitasyon hastaların tedavileri bakımından son aşama olarak değerlendirilir. Erişkin dudak damak yarıklı hastalar için protetik açıdan hastanın mevcut durumunda uygun pek çok tedavi yaklaşımı bulunmaktadır. Hastaya uygun olan yöntemin seçiminde vakanın durumu, daha önce herhangi bir tedavi uygulanıp uygulanmamış olması, büyüme gelişme dönemini tamamlamış olması ve hastanın sosyo-ekonomik durumu etkilidir. Mese ve ark. ${ }^{9}$ sunmuş oldukları vaka raporunda hastanın mevcut dişlerini kullanarak üst çenede defekt bölgesini kapatan hareketli bölümlü protez planlamışlardır. Defekt bölgesi kapatıldığı için hastanın fonksiyonel eksikliklerinini yanında, estetik ve fonasyon 
problemlerinin de giderildiğini bildirmişlerdir. Çalışmamızda, hastanın beklentisi karşılanmış ve hasta memnuniyetinin yüksek olduğu belirlenmiştir. Türkkahraman ve ark. $^{10} 2005$ yılında yayınladıkları çalışmalarında dudak damak yarıklı bireylerde multidisipliner yaklaşımın öneminden bahsetmişlerdir. Hastaya defekt bölgesinin augmentasyonu için kemik grafti uygulamasını takiben sabit restorasyonlar yapılmıştır.

Dudak damak yarıklı bireylerde oral fistülün varlığı ve lokalizasyonu yapılacak olan protezin planlamasını değiştirecektir. Oral fistülün sert damağın ön bölgesinde yer aldığı durumlarda yiyecek ve içeceklerle ilgili problemler yaşanırken, arka tarafına doğru olduğunda hava kaçışı sebebiyle fonasyonla ilgili problemler oluşabilir. Akay ve $a r k .{ }^{5}$ oral fistülü olan vakaya uyguladıkları sabit protezden destek alan hareketli protez ile hasta memnuniyetini sağlamışlardır. Bizim hastamızda da benzer bir protetik tedavi yoluna gidilmiştir ve fistülün akrilik protetik materyal ile kapatılması ile başarılı sonuç elde edilmiştir. Hochman ve ark. ${ }^{11}$ vaka raporlarında çift taraflı dudak damak yarığı olan hastanın rehabilitasyonunda ortodontik tedavi sonrasında hareketli ve sabit protezler kullanmışlardır. Hastanın estetik ve hijyenik problemlerin karşılandığını ve diğer tedavi yaklaşımları ile maliyet açısından kıyaslandığında daha uygun olduğunu bildirmişler. Marti ve ark. ${ }^{12}$ oronasal fistulü olan hastayı Maryland köprü ve silikon obtüratör kullanarak rehabilite etmişlerdir ve hasta sonuçlardan memnun kaldığını bildirmiştir.

Dudak damak defektli hastalarda çoğu zaman

doğumsal veya sonradan uygulanan tedaviler sebebiyle diş eksiklikleri olabilir. Böyle durumlarda hastanın protetik rehabilitasyonunda retansiyon ve stabilite açısından implantlardan faydalanılabilir. Kawakami ve ark. ${ }^{13}$ çift taraflı dudak damak yarığı olan hastalarını ortodontik tedavi sonrasında eksik dişlerinin yerine koymak için dental implantlar ile reabilite etmişlerdir. Hasta memnuniyetinin sabit protezler kullanıldığı için yüksek olduğunu bildirmişlerdir. Abreu ve ark. ${ }^{14} 65$ yaşında, 40 yıl boyunca diş destekli hareketli protez kullanmış olan hastarının periodontal sebepler dolayısıyla dişlerin çekimini takiben, implant destekli hareketli protez planlamışlardır. Hastanın konuşmasında ve diğer fonksiyonlarında belirgin artış olduğunu bildirmişlerdir. Lopes ve ark ${ }^{15}$ maksillada geniş defekt ve eksik dişleri bulunan 41 yaşındaki hastalarına bar ataşman kullandıkları overdenture tarzı bir protez planlamışlardır. Bu tarz bir protez ile hastanın hem fonksiyonel hem de psikolojik eksikliklerinin iyi bir şekilde giderildiğinden bahsetmişlerdir. Vakamızda sosyo-ekonomik nedenler dolayısıyla implant destekli protez yerine konvansiyonel yöntem tercih edilmiştir.

\section{SONUÇ}

Dudak damak yarıklı vakalarda cerrahi tedavi olsun ya da olmasın, eksik dişlerin tamamlanması, oklüzyonun stabilizasyonu, çiğneme ve konuşma fonksiyonunun düzeltilmesi ve alveoldeki defektin rekontrüksiyonu nedeni ile protetik tedavi hedeflenir. Dudak damak yarığı tedavisi multidisipliner bir tedavi yaklaşımı gerektirir. Hasta cerrahi tedaviye uygun değilse veya kabul etmiyorsa, hastanın konforunu en iyi şekilde arttırabilecek hareketli veya sabit protezler planlanabilir.

\section{KAYNAKLAR}

1. Stainer P, Moore GE. Genetics of cleft lip and palate: syndromic genes contribute to the incidence of non-syndromic clefts. Hum Mol Genet. 2004; 13: 73-81.

2. Buğurman $B$, Türker ŞB. Dudak ve damak yarıklı hastalar: etyoloji, embriyoloji, sınıflandırma ve klinik bulgular. Akademik Dental Dişhekimliği Dergisi 2007; 9: 41-4.

3. Gülşen A, Atalay Z, Özel AŞ. Yetişkin dudak damak yarıklı olgularda esteik ve fonksiyonel tedavi yaklaşımı. Gazi Tıp Dergisi 2008; 19: 33-7.

4. Hickey $A J$, Salter M. Prosthodontik and psychological factors in treating patients with congenital and craniofasial defects. J Prosthet Dent 2006; 95: 392-6.

5. Akay C, Karakış D, Yaluğ S. Dudak damak yarıklı hastada estetik ve fonksiyonel protetik rehabilitasyon. Atatürk Üni Diş Hek Fak Derg 2014; 9: 54-60.

6. Jajja M, Ghani A, Cawasji Z, Imran S, Khan M, Hashmi $S$, Khan T. Oral Clefts: A review of the cases and our experience at a single institution. J Park Med Assoc 2013; 63: 1098-2013.

7. Ağaçayak KS, Ağaçayak E, Coşkun S, Aksoy O. Konjenital orofasiyal yarıkla: etyolojisi ve sıklığı. Dicle Med J 2014; 41: 429-33.

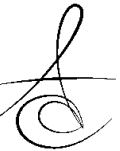


8. Reisberg DJ. Dental and Prosthodontic Care for Patients With Cleft or Craniofacial Conditions. Cleft Palate Craniofac J 2000; 37: 534-7.

9. Mese A, Özdemir E. Removable partial denture in a cleft lip and palate patient: a case report. J Korean Med Sci 2008; 23: 924-7.

10. Türkkahraman H, Sarığlu M, Sayın MÖ, Baykul T, Aydın MA, Nasır S, Eroğlu E. Multidiciplinary treatment of adult patient with unilateral cleft lip and palate: a case report. Turkiye Klinikleri J Dental Sci 2005; 11: 64-8.

11. Hochman N, Yaffe A, Zilberman $Y$, Ehrlich J. Functional and rehabilitation of an adelecent cleft lip and palate patient. Quintessence Int 1991; 22: 401-4.

12. Marti SS, Tessore DM, Henar TE. Prosthetic assessment in cleft lip and palate patients: a case report with oronasal communication. Med Oral Patol Cir Bucal 2006; 11: 493-6.

13. Kawakami S. Yokozeki M, Horiuchı S, Moriyama K. Oral Rehabilitation of an Orthodontic Patient With Cleft Lip and Palate and Hypodontia Using Secondary Bone Grafting, Osseo-Integrated Implants, and Prosthetic Treatment. Cleft Palate Craniofac J 2004; 41: 279-28.

14. Abreu A, Levy D, Rodrigez E, Rivera I. Oral Rehabilitation of a Patient With Complete Unilateral Cleft Lip and Palate Using an Implant-Retained Speech-Aid Prosthesis: Clinical Report. Cleft Palate Craniofac J 2007; 44: 673-7.

15. Lopes JFS, Pinto JHN, Almedia ALPF, Lopes MMW, Dalven GS . Cleft Palate Obturation With Bra nemark Protocol Implant -Supported Fixed Denture and Removable Obturator. Cleft Palate Craniofac J 2010; 47: 211-5.

\section{Yazışma Adresi}

Dr. Ş. Begüm Türker

Marmara Üniversitesi

Diş Hekimliği Fakültesi

34854 Başıüyük, Maltepe

İstanbul, Türkiye

Tel: 02164121621 (1777)

Fax: 02164210291

e-mail: begumturker @ hotmail.com 